SCHRIFTEN

ZUR GESCHICHTE UND KULTUR 4

DER ANTIKE

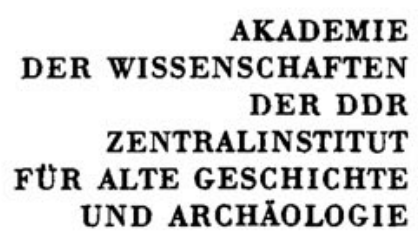

\title{
Columella
}

\section{Über Landwirtschaft}

Ein Lehr- und Handbuch

der gesamten Acker- und Viehwirtschaft

aus dem 1 . Jahrhundert $u$. Z.

Aus dem Lateinischen übersetzt, eingeführt und erläutert von

KARL AHRENS

2., berichtigte Auflage

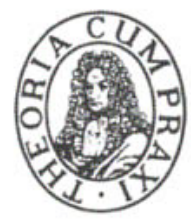

AKADEMIE-VERLAG - BERLIN 1976 
Redaktion: Wolf-Dieter Erfurt

Dietlind Schieferdecker

Erschienen im Akademie.Verlag, 108 Berlin, Leipziger Straße 3-4

(c) Akademie-Verlag Berlin 1972

Lizenznummer: $202 \cdot 100 / 129 / 76$

Offsetdruck und buchbinderische Verarbeitung:

VEB Druckerei „Thomas Müntzer“, 582 Bad Langensalza/DDR

Bestellnummer: $7519862(2143 / 4)$. LSV 4006

Printed in GDR

DDR 48,- M 